\title{
Marcos mentales: ¿marcos morales? Deliberación pública y democracia en la neuropolítica
}

\author{
Mental frames: Moral frames? Public deliberation \\ and democracy in neuropolitics
}

PEDRO JESÚS PÉREZ-ZAFRILLA

Departamento de FIlosofía del derecho, moral y política. Universitat de ValènCia

Artículo recibido: 16 septiembre 2016

Solicitud de revisión: 7 marzo 2017

Artículo aceptado: 7 septiembre 2017

Resumen

En este trabajo trato de abordar el concepto de marco mental como clave para entender la concepción que la neuropolítica tiene de la deliberación pública y la democracia. En un primer lugar expondré los puntos centrales de las teorías de Jonathan Haidt y George Lakoff sobre el marco mental y la deliberación pública. Después pondré en relación la idea del marco mental con el concepto de marco referencial de Taylor. Finalmente, analizaré críticamente el modelo de deliberación pública y de democracia que cabe extraer del concepto de marco mental en la neuropolítica.

Palabras clave: Neuropolítica, marco mental, Lakoff, deliberación pública y democracia.

\begin{abstract}
In this article I address the concept of «mental frame» as the key to understand the conception neuropolithics has on moral deliberation. Firstly, I will expose the core points of Jonathan Haidt y George Lakoff's theories on mental frame and public deliberation. Then, I will put in relation the idea of mental frame with Charles Taylor's concept of «referential frame». This will allow us, finally, to critically analyze the model of public deliberation and democracy that can be drawn from the concept of moral frame in neuropolitics.
\end{abstract}

Keywords: Neuropolithics, mental frame, Lakoff, public deliberation and democracy.

En este trabajo pretendemos abordar el modelo de deliberación pública y de política democrática que se maneja desde la neuropolítica. Para ello nos centraremos en el análisis del concepto de marco mental y de las consecuencias normativas que tiene la aplicación de este concepto sobre la vida política. Comenzamos presentando la idea de marco mental tal 
como es entendida desde la neuropolítica.A continuación abordaremos las limitaciones explicativas que posee este concepto para dar cuenta de la esfera política. Finalmente se analizará críticamente el modelo de política derivado de la aplicación de las tesis de la neuropolítica.

\section{MARCOS MENTALES}

En las últimas décadas ha proliferado la aplicación de los conocimientos neurocientíficos a los diferentes ámbitos de la vida social. Surgen así los saberes neuro, como la neurorreligión, la neuroética, el neuroderecho, etc. Otra de esas formas de aplicación es la neuropolítica (Conill \& Pérez Zafrilla, 2013). Esta última consiste en el estudio del comportamiento político desde las neurociencias. Su tesis central es que nuestro comportamiento político posee una base claramente emocional e inconsciente. De este modo, la neuropolítica, apoyada sobre las nuevas técnicas de neuroimagen, promete aportar un conocimiento fehaciente de las bases inconscientes del comportamiento político y electoral de los ciudadanos. Esto ha hecho que la neuropolítica se haya convertido hoy en una especie de piedra filosofal que permitiría a los políticos dominar el comportamiento político de los ciudadanos sin que estos sean conscientes de ello.

Según algunos neurocientíficos como es el caso de Lakoff o Haidt, la pretendida primacía del pensamiento racional es una ficción mantenida durante siglos en el ámbito teórico. En su lugar, estos autores sitúan las metáforas, las imágenes y otros elementos retóricos como los ejes del comportamiento político (Lakoff, 2009; Ortiz, 2016). Son estos elementos los que permiten llegar a las fuentes intuitivas e inconscientes de nuestros juicios morales y políticos. Ello es así ya que, según entienden, ni nuestra mente ni el lenguaje tienen un contenido objetivo compartido por todos, sino que sus contenidos cobran sentido siempre dentro de unas narrativas. Por ejemplo, las personas que apoyan una guerra no lo hacen calculando los costes y beneficios de ese conflicto para el país. Lo hacen pensando que el enemigo es una amenaza y el presidente es el héroe que quiere protegerles. A su vez las narrativas se componen de marcos. El marco es el sistema conceptual que articula nuestro pensamiento y desde el que entendemos todo lo que nos rodea. El marco articula un relato sobre qué es bueno y qué es malo en torno al tema al que hace referencia. Así, en el caso de la política, el marco es el eje sobre el que el individuo estructura un modelo de sociedad que cree justo. Por ejemplo, la expresión metafórica 
«guerra contra el terror» empleada por G. W. Bush tras el 11-S evoca un marco en el que se presenta algo negativo - la guerra- como opuesto a algo peor - el terror - de tal forma que hacer la guerra al terror pasa a ser bueno. Con ello se genera un marco en el que el enemigo es malo porque provoca terror y quien le combate es bueno porque nos evita el terror.

Ahora bien, el punto clave está en que según los autores de la neuropolítica la adopción de un marco concreto por parte de los sujetos no es fruto de una elección voluntaria y racional, sino que vendría causada por la activación inconsciente de las sinapsis cerebrales en el contexto en que el sujeto se desenvuelve. Esto es así porque los marcos mentales están fijados en redes neuronales. Estas conexiones neuronales se activan en nuestro cerebro al percibir ciertas experiencias del exterior. El cerebro no se limita a registrar hechos de la realidad, sino que los procesa a nivel neuronal. De este modo, al tener una experiencia en el contexto político - la escucha de una metáfora, por ejemplo- nuestro cerebro conecta de forma inconsciente esa metáfora con emociones y pensamientos determinados que se han experimentado junto a la metáfora. Esa conexión queda fijada en unas redes neuronales de asociación que dan lugar a un marco mental (Castells, 2009). Siguiendo con el ejemplo anterior, la expresión "terror» causa miedo paralizante que hace buena a la guerra que lo combate sin importar los medios que utilice. La activación de los marcos es posible gracias a los procesos de refuerzo de las sinapsis neuronales a través de la experiencia reiterada del sujeto y del aprendizaje de pautas de roles sociales y culturales que se inscriben en los circuitos cerebrales (Garrido, 2013). Ello explica que los marcos no sean arbitrarios, sino que se forman a partir de la experiencia y de la organización social que define roles sociales de la comunidad en la que el sujeto se desenvuelve (Castells, 2009).

Esta incardinación de los marcos mentales en redes neuronales resulta esencial. De manera general, gracias a las asociaciones neuronales, cada experiencia que tenemos sobre algo quedará unida de forma inconsciente a unas sensaciones positivas o negativas de aprobación o rechazo, en función de la incidencia que dicha imagen o experiencia tenga sobre nuestro bienestar (Westen, 2007; Lakoff, 2009), como muestra Damasio (2001) con su tesis del marcador somático. Así, al reiterarse una experiencia similar, esas conexiones cerebrales harán aflorar, por un lado, el marco mental en que dicha experiencia cobra sentido para nosotros, y, por otro, la reacción intuitiva de aprobación o rechazo que ese estímulo exterior generó en nosotros, y que da lugar a la actitud que tenemos hacia él (Castells, 2009; Lakoff, 2009; García-Marzá, 2012). 
Mención especial requiere esa reacción intuitiva de aprobación o rechazo, por cuanto que, según los teóricos de la neuropolítica y la neuropsicología, constituye la base de nuestra valoración moral. Lo que nos provoca bienestar se considerará moral y lo que nos causa rechazo se considerará inmoral (Haidt \& Bjorklund, 2007; Westen, 2007; Lakoff, 2009). ${ }^{1}$ Ahora bien, esas reacciones intuitivas no son meramente arbitrarias, sino que responderían a unos patrones adaptativos forjados en nuestro cerebro por la convivencia en grupos pequeños a lo largo de la evolución (Castells, 2009). ${ }^{2}$ Por ese motivo los autores de la neuropolítica sostienen que nuestro comportamiento político y moral es en gran parte inconsciente y responde a las reacciones emocionales positivas o negativas provocadas por el entorno en nuestras sinapsis cerebrales.

En el caso de la deliberación pública, desde la neuropolítica se defiende que el modo más eficaz de activar las conexiones neuronales -que dan forma a los marcos mentales - no es la reflexión consciente sobre argumentos, datos y evidencias, sino justamente el recurso a metáforas, imágenes, los valores, ideas y emociones (Lakoff, 2016). En concreto, las imágenes corresponden a fotos, representaciones gráficas o escenas de televisión que, al llegar a nosotros unidas a ciertas emociones, logran activar regiones concretas del cerebro creando patrones neuronales. De este modo, esas escenas quedan en el imaginario colectivo como símbolo de un problema o suceso político o como recuerdo que identifica a un político o un partido. La importancia de la imagen reside en que transmite un mensaje político que es socialmente aceptado y al que los argumentos contrarios no pueden hacer frente. Un ejemplo sería cuando el candidato republicano Marco Rubio interrumpió una importante intervención televisada en 2013 para beber agua de una botella. Esta escena sería utilizada por sus adversarios - de fuera y dentro del partido - para identificar a Rubio como alguien débil e incapaz de controlar la presión en los momentos difíciles. Tal fue el efecto de esa escena que desde entonces Marco Rubio es recordado como el candidato que bebió agua en un debate. Cómo haya sido su acción polí-

1 En todo caso, los marcos se activan debido a las experiencias personales que, a su vez, son conformadas por la influencia social. Este aspecto será abordado después.

2 Este es un punto en el que los autores divergen. Si bien algunos autores como Gazzaniga (2006) o Mora (2007) defienden que las activaciones neuronales fijan los contenidos de la respuesta moral, otros, como Hauser (2008) o Haidt (2012) se limitan a señalar que el cerebro solo nos proporciona una estructura moral universal cuyos contenidos son modulados por las distintas culturas. En este sentido, Marc Hauser habla de la "gramática moral" inscrita en nuestro cerebro a través de la evolución y que adopta contenidos distintos en cada cultura. Por su parte, Haidt articula esos patrones evolutivos de las intuiciones morales en su propuesta de los seis fundamentos o intuiciones fundamentales de la moral. 
tica como senador resulta irrelevante ante su imagen de debilidad bebiendo agua frente a aquella cámara. ${ }^{3}$

Pero mención especial requieren las metáforas. Estas son, según Lakoff, las estructuras mentales en las que articulamos nuestro pensamiento y que, por medios que abordaremos ahora, se encuentran incardinadas en las sinapsis cerebrales. Las metáforas son las expresiones o lemas que convierten en moneda común los políticos en el foro público (y que logran hacerse moneda común gracias a su incardinación en nuestras redes neuronales). Las metáforas, en la forma de clichés y etiquetas, encasillan elementos como políticas emprendidas, los adversarios políticos o los defensores de ciertas posiciones. Ejemplos de metáforas serían, según Lakoff, «la guerra contra el terror» o el «alivio fiscal» empleadas por los republicanos en los Estados Unidos. Las metáforas dotan a los conceptos de un sentido concreto, al insertarlos en un marco - un relato- acuñado en el cerebro del sujeto.

El objetivo que se persigue con la metáfora es suscitar el rechazo o la aprobación del público de una forma irreflexiva hacia las acciones políticas o hacia los políticos o grupos a los que la metáfora hace referencia. Así, solo con nombrar la metáfora se activará en el público un marco en el que algo se reconoce como bueno o malo de una forma no consciente. Según Lakoff, las causas que posibilitan la capacidad de la metáfora para articular nuestro pensamiento y activar el marco mental son dos: la primera es que la metáfora sea pronunciada en un momento de gran atención política - por ejemplo, la noche electoral. La segunda, y más importante, es la repetición constante de la metáfora en el ámbito público. Esa repetición reiterada en el foro público hace que la activación del circuito neuronal provocada por la metáfora en el cerebro de los oyentes refuerce la sinapsis hasta formar patrones neuronales. Cuando ese patrón se forma, la mera escucha del concepto produce en los individuos, gracias a la activación de la sinapsis, el marco mental que da sentido al concepto al insertarlo en una narrativa. Pero también la activación del marco genera unos flashes de aprobación o rechazo que dan lugar a la valoración moral. Esto es así porque, como muestran Haidt (2001) y Lakoff (2009), la significación moral de los conceptos se reduce a las reacciones emocionales de aprobación o rechazo que esos conceptos producen en nosotros.

3 Ahora bien, en ocasiones sucede que el triunfo de una imagen en un momento dado puede volverse en contra de su creador. Así, la imagen de la estatua de Sadam Husein derribada en Bagdad en 2003 fue utilizada en su momento como símbolo del triunfo del ejército estadounidense en la segunda guerra de Irak. Sin embargo, años después, esa imagen ha representado el comienzo de todo el desastre posterior. 
Pues bien, la capacidad de la metáfora para activar el marco mental, junto con la valoración moral intuitiva en los sujetos, producen de manera no reflexiva la aprobación o rechazo de ciertas posiciones políticas. En este sentido, para los teóricos de la neuropolítica el enmarcado mental posee grandes ventajas que es importante saber aprovechar en la contienda política.

En primer lugar, el enmarcado explica que en los procesos deliberativos las personas no cambien de opinión cuando se les presentan evidencias contrarias a la posición que defienden. Por ejemplo, en un debate sobre la pena de muerte los participantes pueden presentar evidencias que refuercen sus planteamientos, pero esos datos serán incapaces de hacer repensar su posición al interlocutor. Ello se debe a que la posesión de un marco mental hace que solo se acepte como verdadero lo que coincide con ese marco, a la vez que se dejan fuera de la valoración los aspectos de la realidad que quedan fuera del marco o que lo pueden contradecir.

Una segunda ventaja es que, como punto clave, la difusión de la metáfora en la esfera pública y su aceptación inconsciente por el público mediante la activación de las sinapsis cerebrales, permite que el conjunto del público piense a través del marco activado por esa metáfora sobre ese tema concreto. Con ello se consigue que el adversario quede descalificado ante el público, con independencia que sus argumentos tengan más peso que los del grupo creador de la metáfora. Por ejemplo, como señala Lakoff, al triunfar la metáfora del «alivio fiscal» en el tema de los impuestos, se impuso en la opinión pública el marco de que los impuestos son malos y que quien promete reducirlos es bueno. En consecuencia, todo aquel que apoye una subida de impuestos quedará descalificado desde el comienzo y sus argumentos caerán en saco roto.

Finalmente, una tercera ventaja, derivada de la anterior, es que al devenir imperante un marco, cualquier intento del oponente de negar ese marco desde dentro está condenado al fracaso. Ello es así por dos motivos. En primer lugar, porque, como acabamos de señalar, el rechazo que generará ese oponente entre la ciudadanía es previo a la argumentación. ${ }^{4}$ La segunda razón es que cualquier intento del oponente de negar ese marco imperante con argumentos que encajan en ese marco solo conseguirá reforzar a este. En palabras de Lakoff: «si mantienes su lenguaje y su marco, y te limitas a argumentar en contra, pierdes tú, porque refuerzas su marco» (Lakoff, 2007: 58).

4 De esta forma también, las metáforas evitan al grupo que las difunde el tener que confrontar ideas $\mathrm{y}$ argumentos con sus oponentes. 
Pero si eso es así, ¿no existe entonces forma de vencer la preeminencia de un marco en el foro público? Para Lakoff sí la hay. Esto se puede conseguir de dos modos. El primero de ellos es confrontar el marco imperante con argumentos de tu propio marco para que el marco del oponente no sea el aceptado como común. El segundo método es difundir reiteradamente un concepto metafórico alternativo que evoque nuestro marco en el ámbito público hasta hacerlo hegemónico mediante la activación y reforzamiento de las sinapsis. En ambos casos, como se ve, la respuesta a un marco debe ser siempre desde fuera del mismo y dirigida a imponer el nuestro. No obstante, con todo ello, resulta fácil advertir que este concepto de metáfora no hace sino recuperar la idea orwelliana expuesta en 1984: de lo que no se puede hablar, no se puede pensar ni tampoco cuestionar. Esta concepción de la metáfora será, en mi opinión, uno de los aspectos más cuestionables de la neuropolítica, como defenderé más adelante.

Este recurso a los marcos mentales, así como la centralidad de las metáforas en el discurso público arrojan varias consecuencias fundamentales sobre la concepción que la neuropolítica posee del proceso deliberativo y el proceso político, y que analizaremos más adelante. Ahora abordaremos unas limitaciones que posee el concepto de marco mental para dar cuenta de la vida política.

\section{MARCOS MENTALES Y MARCOS MORALES}

El modo en que desde la neuropolítica se abordan los procesos deliberativos posee una gran relevancia, ya que pone de relieve dos aspectos fundamentales. Por un lado, el papel que en nuestro pensamiento moral adquieren las emociones, algo no siempre reconocido desde la filosofía, pero que en la actualidad ya viene defendiéndose desde ciertos planteamientos como el de la «razón cordial» de Cortina (2007) o el de la «imparcialidad afectiva» de Krause (2008). Pero en segundo lugar, la neuropolítica ha revelado también que nuestro pensamiento moral no se rige por una razón universalmente compartida, sino que es mucho más limitado. Se articularía en torno a marcos mentales impermeables a las evidencias contrarias y dentro de los cuales los distintos términos adquieren un sentido concreto.

Ahora bien, partiendo de estos aciertos de la neuropolítica, reconocer el papel de las emociones en la deliberación moral y que los juicios morales adquieren sentido solo dentro de unos «marcos», no implica necesaria- 
mente que los procesos deliberativos se guíen por los patrones puramente emotivistas que describen autores como Lakoff y, sobre todo, Haidt. Estos autores pueden aportar una explicación plausible de nuestro comportamiento moral, pero ello no implica que esa explicación sea la correcta. Pensemos por ejemplo en la tesis del Haidt sobre el «desconcierto moral». Que ante ciertas situaciones los sujetos no sean capaces de articular una explicación convincente no implica de manera necesaria que los juicios tengan un origen intuitivo, como cree Haidt (Haidt, Kollert \& Dias, 1993). Ese hecho se puede explicar de una manera más clara aludiendo simplemente a la heteronomía de muchos de nuestros juicios en multitud de áreas, como las ciencias, la historia o la moral (Cortina, 2011; Levi, 2007; Pérez Zafrilla, 2013).

Pues esto que sucede con el desconcierto moral puede aplicarse también a la idea de los marcos mentales. Para empezar, decir que las personas piensan en términos de «marcos (mentales)»-y que dichos marcos poseen un correlato neuronal- ni es una novedad en el ámbito teórico, ni por sí mismo excluye el carácter netamente moral de nuestro pensamiento. Más bien habría que afirmar que los autores de la neuropolítica tratan de apoyar sobre evidencias científicas - aunque con un erróneo propósito reduccionista - algo que se viene defendiendo en la filosofía desde tiempo atrás. De hecho, el rechazo del modelo de razón universalmente compartida es un elemento característico de corrientes filosóficas como la hermenéutica o la tradición comunitarista. Autores como Gadamer (2001), MacIntyre (1987) o Taylor (1996a), pero también desde la democracia deliberativa, como Gutmann y Thompson (1997) o Gerald Gaus (1996), han señalado, de distinta forma, que nuestro pensamiento se articula en torno a marcos proporcionados por la comunidad a la que pertenecemos. En esos marcos los distintos términos adquieren su sentido propio.Así, también, estos mismos autores apuntan a las diferencias entre los marcos como clave del desacuerdo moral. De esta forma el recurso al comunitarismo o a la hermenéutica nos puede dar una de las claves para entender cómo la explicación neuropolítica no agota la comprensión de la deliberación, pues olvida la dimensión moral de esta.

Por poner el acento en un caso significativo, el filósofo Charles Taylor emplea el mismo concepto de marco. Concretamente habla de «marcos referenciales» (Taylor, 1996a: 20), y lo hace precisamente en respuesta a las tesis de uno de los primeros autores de la neuroética, Edward O. Wilson, autor de la corriente sociobiológica de los años setenta del siglo xx. Wilson, como harán autores posteriores como los estudiados aquí, reduce la valo- 
ración moral a una respuesta afectiva forjada en nuestro cerebro a través de la evolución y dirigida a mantener la supervivencia (Cortina, 2010; 2013a; 2013b). Para la teoría sociobiológica del comportamiento moral, las reacciones morales son despojadas de cualquier sentido más allá del adaptativo. De esta manera, pretender reconocer en el mundo cosas dignas de respeto moral sería una mera ilusión, al igual que le parece ilusorio a Haidt pensar que nuestros juicios morales son fruto de un razonamiento o que es posible el convencimiento racional.

Pero esta idea, según Taylor, supone no comprender la fenomenología moral. Según él, nuestro comportamiento moral no responde a meras reacciones adaptativas, que reducen el valor a la sensación de placer o bienestar que los estímulos producen en nosotros o, dicho de otro modo, a lo útiles que esos estímulos resulten para nuestra supervivencia. Como ya señalara Ortega (1947), no es propiamente nuestra proyección de sensaciones la que hace a las cosas valiosas, sino que las cosas son valiosas por sí mismas con independencia de que nosotros las deseemos. El valor es una propiedad que se nos presenta de forma imperativa y que reconocemos como tal por su dignidad, con independencia de nuestros deseos o inclinaciones. De hecho, el valor moral se presenta en muchas ocasiones en franca oposición a los comportamientos a que nos inclinan las reacciones adaptativas. Estas nos llevarían, por ejemplo, a considerar moral la ayuda a los cercanos y el rechazo de los lejanos, pues solo de los primeros podemos esperar reciprocación y que nuestra ayuda no sea en balde. Sin embargo, este supuesto principio choca con el valor inmoral que en nuestra sociedad adquieren el nepotismo o la xenofobia. Por ello, no parece razonable extraer del es cerebral un debe moral, pues de lo contrario estaríamos recayendo en la conocida falacia naturalista (Cortina, 2010; 2011).

De este modo, nuestra valoración moral estará situada más allá de nuestro interés adaptativo. Según Taylor (1996a), la valoración moral está dentro de un marco referencial que da sentido a nuestras vidas. Ese marco moral no se asienta en respuestas intuitivas a los estímulos recibidos del exterior como se entiende desde los diferentes enfoques neurocientíficos, ${ }^{5}$ sino que está constituido por unos bienes a los que reconocemos una dignidad y valor superior independientes de nuestros deseos o inclinaciones. En este sentido, el marco referencial es el horizonte de lo moralmente significativo para nosotros. Pero, sobre todo, ese marco de la significación moral se ca-

5 Unos autores como Dawkins (1997) reducen la moral a las respuestas adaptativas forjadas por la evolución para favorecer la propia supervivencia. Otros como Haidt (2012) interpretan la moral como la forja de respuestas que favorecen la supervivencia del grupo. 
tegoriza desde el reconocimiento de un modo de vida como cualitativamente superior al resto. Los marcos proporcionan a las personas tanto lo que reconocen como valioso como el sentido mismo que adquiere lo valioso para cada persona. El marco referencial representa los supuestos inherentes a nuestros juicios morales y de los que los sujetos no son del todo conscientes al realizar sus juicios. ${ }^{6}$

Por otro lado, la posesión de un marco referencial para nuestros juicios morales no es algo arbitrario ni fruto de una elección gratuita. Nuestro marco moral viene dado, según Taylor, por aquellos colectivos con los que estamos fuertemente comprometidos y que conforman también nuestra identidad. Es desde su pertenencia a tales grupos como el sujeto se alfabetiza moralmente. No en vano, una tesis central de la teoría comunitarista (Taylor, 1996b) será que la identidad personal se forma siempre por su relación con otros sujetos y, en particular, por el reconocimiento que recibe de sus semejantes. Esos grupos nutren, por tanto, el marco en el que la realidad tiene sentido para el sujeto, ya que fijan el significado que adquirirán los propios términos - morales. De este modo, según Taylor, las personas se mueven en el espacio moral siempre dentro de marcos generados dentro de las comunidades a las que pertenecen. Una consecuencia de esto será que los marcos morales difieran entre las personas o que incluso las personas puedan cambiar de marco moral a lo largo de sus vidas. Las personas cambian de marco referencial cuando reconocen en el marco de otro grupo un sentido superior de lo valioso. Esto sucede, por ejemplo, cuando las personas cambian de religión. Las personas no lo hacen por un acto de voluntad gratuito, sino porque reconocen en el horizonte referencial de esa otra religión un valor superior al marco de valor de su religión actual.

Los marcos referenciales de Taylor nos proporcionan también las claves para entender el pluralismo moral. Los marcos articulan una ontología moral desde la que las personas se aproximan a la realidad y desde la que reconocen unos bienes como superiores. Pero en nuestras sociedades modernas conviven grupos diversos o, en términos de Rawls (1993), doctrinas comprehensivas, con las que se identifican los sujetos. En ellas se reconocen bienes diferentes que pueden llegar a ser opuestos o incluso inconmensurables. De esta forma, los marcos que articulan el pensamiento moral de las personas de diferentes grupos son distintos y estarán enfrentados en su ontología moral.

6 Este maro referencial es propiamente un marco moral, frente al "marco mental" de la neuropolítica. Emplearé los conceptos de marco referencial y marco moral como sinónimos. 


\section{EL FENÓMENO MORAL DESDE LA NEUROPOLÍTICA}

Esta idea de marcos referenciales nos permite advertir las limitaciones con que cuenta el concepto de marco mental para explicar el fenómeno político. Ello radica en que el marco mental no da verdadera cuenta de la dimensión moral de la política. Comenzaré explicando por qué autores como Lakoff o Haidt no dan debida cuenta del mundo moral. Esto nos ayudará a comprender mejor cuál es el ámbito propio de los marcos mentales.

Un error de estos autores reside en el empleo de una metodología claramente reduccionista, que extrae consecuencias normativas de carácter emotivista a partir de un mero estudio de las bases psicofísicas del pensamiento moral: en concreto, la tesis de que esos procesos psicofísicos constituyen en sí mismos la valoración moral. Para Lakoff y Haidt la valoración moral queda reducida a la respuesta automática e inconsciente a estímulos emocionales recibidos del exterior. En consecuencia, el juicio moral sería fruto de una concatenación de procesos psicológicos ajenos al control del sujeto. De este modo, las personas son conscientes de los juicios morales que realizan, pero los motivos reales por los que los hacen permanecen por completo ajenos a su control.Así también, las razones que aportan en la deliberación serían todas ellas fruto de una confabulación de la que el sujeto no es consciente. La persona se encontraría así ante lo que Cortina denomina «esquizofrenia moral» (Cortina, 2011: 107).

No obstante, resulta evidente que este análisis psicologista de Haidt y Lakoff no se corresponde con la forma en que las personas realizan juicios morales en la realidad. Como se señalaba en la sección anterior, proporcionar una explicación plausible no implica que esa sea la explicación correcta. Ciertamente, al realizar juicios morales tiene lugar una concatenación de procesos psicológicos que dan lugar a la emisión de un juicio moral. Pero eso hace referencia a las «bases» del juicio moral, no a los «fundamentos» de este (Cortina, 2011). Porque no realizamos juicios solo porque se activen unas sinapsis cerebrales, igual que no decidimos estudiar una carrera y no otra porque se activen unas sinapsis en nuestro cerebro. Todo nuestro comportamiento tiene una base neuronal, pero esta no agota su explicación, y las decisiones y juicios los hacemos teniendo en cuenta un abanico de factores que van más allá de la base psicofísica neuronal.

El juicio moral se lleva a cabo desde el discernimiento de los elementos que se reconocen como presentes en el caso. Como afirma Cortina (2010, 2012), siguiendo la tesis de Aristóteles (2000), la valoración moral es un 
proceso complejo. El juicio parte de una deliberación razonada mediante la que la persona sopesa diversos factores de la realidad y deja otros aparte. Por ejemplo, como nos recuerda Aristóteles con su distinción entre las acciones voluntarias y no voluntarias, al valorar moralmente la acción de un tercero atendemos a si es posible atribuir intencionalidad a su acción o si, en caso contrario, esa acción no es intencionada. O también, en el famoso caso del trolley dilema, el sujeto protagonista decidiría si empuja a la persona obesa a la vía teniendo en cuenta aspectos como el miedo a ser acusado de asesinato, el conocimiento que tenga de la persona obesa o de los sujetos que hay en la vía, o quizá el miedo a que la persona obesa se dé la vuelta y le arroje a él. Por ese motivo el juicio moral no tiene lugar de una forma intuitiva sino reflexiva. Porque valoramos aplicando un discernimiento que nos hace reconocer como valiosos unos aspectos de la realidad y no otros.

Ahora bien, es fundamental entender que la persona realiza ese balance reflexivo de factores no desde lo que es adaptativamente conveniente para la especie, sino desde lo que el sujeto reconoce como moralmente significativo dentro de un marco de valor determinado. Así el juicio fruto de la deliberación tiene como fin encontrar la mejor respuesta posible, pero siempre desde unas variables determinadas. En todo caso, lo moralmente significativo es algo que el sujeto reconoce no meramente mediante el razonamiento frío, sino también desde la emoción. Señala Krause (2008) que aquello que reconocemos como injusto se define desde lo que nos preocupa y esto se reconoce desde los sentimientos morales. Es decir, lo que reconocemos como bueno o malo se forja desde una conjugación de emoción y razón, sin que sea necesario elegir entre una o la otra. En este mismo sentido, Adela Cortina $(2007,2011)$ ha mostrado que hay unas emociones morales, como la indignación o la vergüenza, que nos revelan la existencia de una relación moral entre las personas, una relación moral basada en una expectativa recíproca impersonal de buena voluntad y en la que todas las personas merecen un trato digno (Cortina, 2011). ${ }^{7}$ De este modo, esas emociones morales nos ayudan a reconocer que ante ciertas situaciones alguien está violando esa expectativa recíproca de buena voluntad, apareciendo así ante nosotros la injustica, que antes nos podía pasar desapercibida. En consecuencia, ese reconocimiento de la injusticia no se

7 Por ese motivo no toda apelación a las emociones es legítima. Solo lo serán aquellas que respeten los principios éticos de simetría y reciprocidad que caracterizan la relación moral. Todas aquellas apelaciones que violen esos principios son formas de manipulación dirigidas a imponer los propios intereses y, por tanto, no son aceptables. 
hace por los impulsos emocionales o la activación de ciertas regiones cerebrales, sino porque nuestra razón cordial sepa reconocer las situaciones de injusticia, de necesidad o de opresión en los momentos apropiados y saber descartar esos sentimientos morales en aquellas situaciones que no lo merecen -como las situaciones de manipulación, abuso o engaño.

En síntesis, Haidt y Lakoff pretenden explicar el mundo moral reduciéndolo a impulsos e intuiciones inconscientes cultivadas en el cerebro a través de la evolución y la influencia cultural del entorno. Es más, ciertos neurocientíficos como Gazzaniga creen que esta sería una explicación correcta, al estar apoyada sobre evidencias científicas. Ello permitiría a las teorías neurocientíficas sustituir las reflexiones llevadas a cabo durante siglos por la religión y la filosofía sobre la realidad moral de la persona (Gazzaniga, 2006; Cortina, 2011). No obstante, como vemos, esta misión naufraga debido a su reduccionismo metodológico.

\section{MARCOS MENTALES Y DEMOCRACIA EN LA NEUROPOLÍTICA}

Esta ceguera de la neuropolítica hacia el mundo moral nos permite comprender el verdadero ámbito de aplicación de los marcos mentales. Para analizar este punto conviene partir de la concepción bastante peculiar que Haidt y Lakoff poseen de la metáfora.Ambos, en lugar de reconocer en la metáfora una capacidad para conectar a la persona con una fuente de valor moral, parecen reducirla a las connotaciones que poseen ciertos términos en el ámbito social y que remiten a marcos fijados en nuestro cerebro. Según estos autores, esas connotaciones metafóricas producen en el oyente la aprobación o rechazo emocional en función de la capacidad de la metáfora para activar nuestras sinapsis cerebrales. De esta forma, la metáfora enmarca el modo en que ciertos problemas son entendidos en la sociedad mediante el uso de ese concepto. Por ejemplo, al imponerse la metáfora «la guerra contra el terror» la guerra será percibida como necesaria por un conjunto de americanos.

Ahora bien, en mi opinión el proceso de enmarcado remitiría a una dimensión no propiamente moral sino más bien prudencial: la forja de la agenda política. Que un problema a nivel político o social quede «enmarcado" desde unos términos concretos en ese nivel social, significa que se han creado las circunstancias - psicológicas- que condicionan a los sujetos a enfocar el asunto desde dichos conceptos. El enmarcado delimita el 
modo en que está bien considerado referirse a tal o cual tema a un nivel convencional.

Dicho de otro modo: la metáfora, activando el marco mental al que remite, genera en los oyentes unas sensaciones que advierten emocionalmente a estos de las consecuencias que tiene a nivel social referirse a un tema con un concepto y no con otro. Cuando a nivel social triunfa una metáfora, el sujeto reconoce intuitivamente que utilizar un concepto diferente arrojará unas consecuencias negativas sobre él, pues el resto de individuos - que comparten el marco hegemónico- sentirán un rechazo intuitivo hacia él por contravenir lo socialmente aceptado. En consecuencia, utilizar un concepto diferente para referirse a un tema, o defender una postura que contravenga el marco generado por la metáfora hará que el resto del grupo lo rechace sin ni siquiera pensar si tal vez los argumentos de ese individuo son mejores. Esto sucede porque la activación de los marcos mentales remite a unos códigos adaptativos forjados por la evolución en nuestro cerebro que nos impulsan a actuar de tal forma que procuremos la aprobación de los demás y evitar su rechazo. Estas emociones, como, por ejemplo, la tendencia a la reciprocación o el altruismo, eran esenciales para la supervivencia en grupos pequeños (Cortina, 2010). Por ese motivo quien se opone al marco se siente incómodo, porque contraviene esos impulsos forjados por la evolución que ligan al individuo al grupo. Ahora bien, si aceptamos estos planteamientos de la neuropolítica, el marco mental no articula relaciones morales. Más bien delimita el nivel de lo socialmente establecido. Esto explica que para Lakoff en política sea tan importante fijar el marco de un concepto y que no lo haga el adversario, para que deba ser este quien se vea forzado por las circunstancias de presión social a adoptar nuestra visión de la realidad.

Este hecho revela otro aspecto del enmarcado: este representa una forma de acción política basada en la racionalidad estratégica. Esto es así por dos motivos.

El primero es que el enmarcado tiene como objetivo la dominación -en la terminología habermasiana- es decir, lograr imponer la propia visión de la realidad y los propios intereses sobre el resto de colectivos, para, con ello, lograr la hegemonía política y social. En palabras de Lakoff: «La batalla política es una batalla de enmarcados» (Lakoff, 2009: 148). En este mismo sentido: «una vez que tu marco se acepta dentro del discurso, todo lo que dices es sencillamente sentido común. ¿Por qué? Porque el sentido común es eso: razonar dentro de un lugar común, de un marco aceptado» (Lakoff, 2007: 166). Con el triunfo del propio marco, el grupo hegemónico consi- 
gue que sus intereses sean aceptados por la sociedad como expresión del interés general.

Por eso también para estos autores los procesos deliberativos están dirigidos al triunfo y no al acuerdo, que es el ámbito propio de la razón comunicativa. Efectivamente, según las tesis de la neuropolítica en la deliberación se llega al acuerdo cuando un interlocutor logra hacer que su adversario cambie de actitud y adopte una similar a la propia. Esto se consigue no mediante la argumentación racional, sino mediante el empleo de la metáfora adecuada que active en el interlocutor el marco que nosotros empleamos para enfocar el problema. Dicho de otro modo, solo será posible llegar a un acuerdo en la deliberación cuando nuestro interlocutor adopte nuestro marco mental gracias a la generación de las intuiciones adecuadas. Esto es así porque el objetivo de los sujetos en el proceso deliberativo es propiamente ganarlo, no llegar a un acuerdo en torno a la solución más justa para todos los afectados, como se defiende desde la democracia deliberativa. En la batalla de marcos solo cabe ganar o perder, porque solo puede imponerse la visión de la realidad - y con ella, los intereses- de uno de los grupos. ${ }^{8}$

La segunda razón es que los medios para lograr la hegemonía son, como los ejemplos de Haidt y Lakoff ponen de manifiesto, propios de la razón estratégica: la repetición reiterada - en otras palabras, la indoctrinación- y la manipulación emocional a través del empleo de metáforas. En palabras de Haidt: «cada argumento es en realidad un intento de enmarcar el asunto con el fin de presionar un botón emocional, provocando diversos flashes de intuiciones en el oyente» (Haidt \& Bjorklund, 2007: 192), y enmarcar no es otra cosa que activar ciertas redes neuronales que producen un determinado marco, el que interesa al hablante (Castells, 2009).

Estos métodos de la repetición reiterada y la manipulación emocional tienen como objetivo ejercer una presión y forzar la incomodidad entre quienes no comparten ese marco para que acaben asumiéndolo. Esta aceptación acomodaticia se presentará ante estas personas como la única forma de ser aceptados por ese grupo hegemónico que impone su visión de la realidad.

8 De esta forma, Lakoff y Haidt no hacen sino retomar el enfoque gramsciano sobre la acción política, ahora desde una base neurocientífica. La acción política para Gramsci no consistía sino en la lucha por la hegemonía cultural, es decir, el liderazgo intelectual, político y moral que permite a la clase dominante articular los intereses colectivos en torno a sus propios intereses - los de esa clase dominante. Porque el poder político no lo aporta la dominación —el ejercicio de la coerciónsino el dominio del discurso público que define lo comúnmente aceptado en la sociedad. 
Esta lógica hacia el triunfo y no hacia el acuerdo que guía el proceso político posee una importancia fundamental para los autores de la neuropolítica. Muchos neurocientíficos tienen como una de sus dedicaciones principales el neuromarketing electoral, dirigido a asesorar a los políticos, entre otras cosas, sobre cómo deben hablar en público para que el marco mental de su partido sea preponderante entre la ciudadanía al pensar sobre los diferentes temas y obligar de este modo al adversario a asumirlo (Lakoff, 2007; Alcántara, 2014).

Ahora bien, frente a esa inducción emocional al acomodamiento del adversario a lo socialmente establecido, la política democrática se caracteriza precisamente por apelar a un nivel contrafáctico que puede cuestionar lo establecido socialmente. Limitar la política a la imposición de marcos mentales es un grave error, ya que supone no comprender realmente la dimensión moral de la política. Por un lado, porque implicaría reducir la moral a mandatos hipotéticos dirigidos a obtener la aprobación social por parte de los grupos hegemónicos que establecen lo que es aceptable o no. Por otro, porque atenta contra la capacidad crítica que define a la esfera de la moralidad y que permite evaluar si lo establecido socialmente se adecúa o no a unos principios de justicia. Porque enmarcar un mensaje mediante la repetición machacona de consignas no nos dice nada acerca de la justicia de su contenido (García-Marzá, 2012).

No se puede olvidar tampoco que, en el ámbito político democrático, el modo correcto de defender lo justo es la argumentación racional -aunque no una razón ciega a las emociones - y no precisamente la indoctrinación. Porque esta, guiada por la razón estratégica, tiene como objetivo que una de las partes imponga sus intereses sobre el resto, no respetando así la relación de simetría presente en toda relación dialógica regida por la razón comunicativa. De ahí que toda forma de imposición o manipulación para hacer triunfar la posición propia a toda costa resulte inmoral e impropia de un proceso deliberativo democrático.

En este mismo sentido, este modelo que reduce la política al logro de hegemonías a través de la manipulación emocional creadora de marcos mentales, transmite una concepción bastante pobre de la política y de la ciudadanía: una élite política se dedica a inculcar contenidos ideológicos en una masa de ciudadanos concebidos como menores de edad, mediante el recurso a consignas, etiquetas e ideas simples hasta hacer esas ideas hegemónicas. Al mismo tiempo, se impide que esas ideas hegemónicas puedan ser cuestionadas racionalmente en el foro público por parte de la misma ciudadanía (Cortina, 2013c). No es de extrañar, por tanto, que Lakoff 
se oponga abiertamente al modelo deliberativo de la Ilustración, basado en la argumentación racional. Lo que él no confiesa es que apuesta por otro modelo claramente preilustrado, impulsor de la heteronomía y la razón perezosa entre la ciudadanía y que permite a unas elites políticas dominar al público y evitar la debida rendición de cuentas. Pero esta concepción, heredera del paradigma democrático elitista (Schumpeter, 1968), resulta inaceptable en la actualidad. En su lugar, se debe fomentar un modelo de democracia en el que se reconozca a los ciudadanos como poseedores de la legitimidad política y en el que impere un principio de rendición de cuentas ante el que deben someterse los políticos, como se señala desde la democracia deliberativa (Gutmann \& Thompson, 1997) o comunicativa (Cortina, 2013c). En consecuencia, ese recurso al «enmarcado», lejos de ser considerado el método adecuado de deliberación pública en las sociedades democráticas, debe ser reemplazado por otras formas que contribuyan al empoderamiento de la ciudadanía.

\section{CONCLUSIÓN}

Como hemos podido comprobar a lo largo de estas páginas, estas innovadoras propuestas desarrolladas desde la neuropolítica pretenden asentar la deliberación moral en procesos de manipulación emocional mediante la generación de intuiciones y la activación de marcos mentales. Sin embargo, este enfoque, al mismo tiempo, saca a la luz sus limitaciones. Entre ellas cabe destacar, por un lado, el carácter reduccionista de su planteamiento, como se comprueba con sus concepciones de los marcos mentales o las metáforas, incapaces de agotar el fenómeno moral. Por otro lado, está su naturaleza falaz, con su intento de asentar nuestra moralidad en el cerebro. Pero también sobresale su apuesta latente por una razón instrumental, al pretender convertir el proceso deliberativo democrático en una lucha de fuerzas dirigida a la imposición de una visión de la realidad -el marco mental- sobre el interlocutor. Es más, la imposición del marco se hace por medios propios de la razón estratégica, como es la indoctrinación y el uso de etiquetas. Todo ello hace que esta concepción de la deliberación pública sea errónea a la vez que rechazable en nuestras sociedades posconvencionales.

Por tanto, se debe rechazar el modelo de deliberación pública y de democracia que se derivan de la neuropolítica. Respecto a lo primero, porque la neuropolítica se revela incapaz de dar una explicación convincente de 
la deliberación pública, al no tener en cuenta el mundo moral. Por lo que se refiere a su modelo de democracia, simplemente no está a la altura de lo exigible en nuestras sociedades, donde el protagonismo de la ciudadanía y la sociedad civil, así como la rendición de cuentas de los responsables públicos, constituyen valores irrenunciables (Cortina, 2013c). En este sentido, solo la apuesta por un modelo más deliberativo de democracia permitirá realizar de forma efectiva estos valores y evitar los peligros a los que abocan las formas elitistas de democracia, ayudadas ahora por sus nuevos aliados, los neurocientíficos.

\section{BIBLIOGRAFÍA}

Alcántara Sáez, Manuel (2014). Neuropolítica: una aproximación a la micropolítica. Revista Española de Ciencia Política, 35, 31-55.

Aristóteles (2000). Ética a Nicómaco. Madrid: Gredos.

Castells, Manuel (2009). Comunicación y poder. Madrid:Alianza.

Cohen, Joshua (1986). An epistemic conception of democracy. Ethics, 97 , 26-38.

Conill Sancho, Jesús \& Pérez Zafrilla, Pedro Jesús (2013). Retos actuales de la neuroética. Recerca. Revista de Pensament $i$ Anàlisi, 13, 5-9.

Cortina, Adela (2007). Ética de la razón cordial. Oviedo: Nobel.

Cortina, Adela (2010). Neuroética: ¿Las bases cerebrales de una ética universal con relevancia política? Isegoría, Revista de Filosofía Moral y Política, 42, 129-148.

Cortina, Adela (2011). Neuroética y neuropolítica. Sugerencias para la educación moral. Madrid: Tecnos.

Cortina,Adela (2012). Neuroética: presente y futuro. En Cortina,Adela (ed.): Guía Comares de Neurofilosofía Práctica (9-37). Granada: Comares.

Cortina, Adela (2013a). ¿Para qué sirve realmente la ética? Barcelona: Paidós.

Cortina, Adela (2013b). ¿Es la biomejora moral un imperativo ético? Siste$m a, 230,3-14$.

Cortina,Adela (2013c). Ética del discurso: ¿un marco filosófico para la neuroética? Isegoría. Revista de Filosofía Moral y Política, 48, 127-148.

Damasio, Antonio (2001). El error de Descartes. Barcelona: Crítica.

Dawkins, Richard (1997). El gen egoísta: las bases biológicas de nuestra conducta. Barcelona: Salvat.

Gadamer, Hans-Georg (2001). Verdad y método. Salamanca: Sígueme. 
García-Marzá, Domingo (2012). Neuropolítica: una mirada crítica sobre le neuropoder. En Cortina, Adela (ed.) (2012). Guía Comares de Neurofilosofía Práctica (77-96). Granada: Comares.

Garrido Rubia,Antonio (2013). La mente política: Neurociencia en las campañas electorales. Ponencia presentada en el XI Congreso de la AECPA, Sevilla.

Gaus, Gerald (2001). Justificatory liberalism: an essay on epistemology and political theory. Nueva York: Oxford University Press.

Gazzaniga, Michael (2006). El cerebro ético. Barcelona: Paidós.

Greene, Joshua (2013). Moral tribes. Emotion, reason, and the gap between us and them. Londres: Atlantic Books.

Gutmann, Amy \& Thomoson, Dennis (1997). Democracy and disagreement. Cambridge: Belknap Press of Harvard University Press.

Haidt, Jonathan \& Bjorklund, Friedrik (2007). Social Intuitionists answer six questions about moral psychology. En Sinnot-Amstrong, Walter (ed.). Moral Psychology, vol. 2. Massachusetts:The MIT Press.

Haidt, Jonathan (2001). The emotional dog and its rational tail. A social intuitionist approach to moral judgement. Psychological Review, 108, 814-834.

Haidt, Jonathan (2012). The righteous mind. Why good people are divided by politics and religion. Nueva York: Pantheon Books.

Haidt, Jonathan, Koller, Silvia \& Dias, Maria (1993). Affect, culture and morality or is it wrong to eat your dog.Journal of Personality and Social Psychology, 65, 613-628.

Krause, Sharon (2008). Civil passions. Moral sentiment and democratic deliberation. Princeton: Princeton University Press.

Lakoff, George (2007). No pienses en un elefante. Lenguaje y debate politico. Madrid: Editorial Complutense.

Lakoff, George (2009). The political mind. A cognitive scientist guide to your brain and its politics. Nueva York: Penguin Books.

Lakoff, George (2016). Language and emotion. Emotion Review, 8(1), 1-5. Levy, Neil (2007). Neuropolitics. Cambridge: Cambridge University Press.

MacIntyre, Alasdair (1987). Tras la virtud. Barcelona: Crítica.

Mercier, Hugo \& Sperber, Dan (2011). Why do humans reason? Arguments for an argumentative theory? Behavioural and Brain Sciences, 34, 57-111.

Mora, Francisco (2007). Neurocultura. Madrid:Alianza.

Ortega y Gasset, José (1947). Introducción a una estimativa. ¿Qué son los valores? En Obras completas, VI. Madrid: Revista de Occidente. 
Ortiz de Landázuri, Carlos (2016). El error neurocientífico de Descartes, entre Spinoza y Tomás de Aquino. El debate entre Damasio y Stump sobre el materialismo eliminativo en la neuroética, neuropolítica y neuroeconomía. Recerca. Revista de Pensament i Anàlisi, 18, 107-133.

Orwell, George (2008). 1984. Barcelona: Destino.

Pérez Zafrilla, Pedro Jesús (2013). Implicaciones normativas de la psicología moral: Jonathan Haidt y el desconcierto moral. Daimon. Revista Internacional de Filosofía, 59, 9-25.

Rawls, John (1993). El liberalismo político. Barcelona: Crítica.

Rodríguez Prieto, Rafael, \& Seco Martínez, José María (2007). Hegemonía y democracia en el s. xxi. Cuadernos Electrónicos de Filosofía del Derecho, 15. Extraído de: http://www.uv.es/CEFD/15/rodriguez.pdf. [Consultado 13 de julio de 2016].

Schumpeter, Joseph (1968). Capitalismo, socialismo y democracia. Madrid:Aguilar.

Taylor, John (1996a). Las fuentes del yo. La construcción de la identidad moderna. Barcelona: Paidós.

Taylor, John (1996b). Identidad y reconocimiento. Revista Internacional de Filosofía Política, 7, 10-19.

Westen, Drew (2007). The political brain. The role of emotion in deciding the fate of the nation. Nueva York: Public Affairs. 